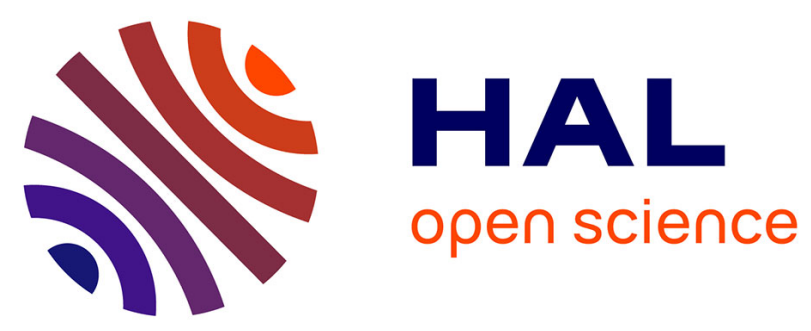

\title{
Temperature effect on the absorption spectrum of the hydrated electron paired with a lithium cation in deuterated water
}

M. Lin, Y. Kumagai, I. Lampre, F.-X. Coudert, Y. Muroya, A. Boutin, M. Mostafavi, Y. Katsumura

\section{To cite this version:}

M. Lin, Y. Kumagai, I. Lampre, F.-X. Coudert, Y. Muroya, et al.. Temperature effect on the absorption spectrum of the hydrated electron paired with a lithium cation in deuterated water. Journal of Physical Chemistry A, 2007, 111 (18), pp.3548-3553. 10.1021/jp070615j . hal-00145214

\section{HAL Id: hal-00145214 https://hal.science/hal-00145214}

Submitted on 10 May 2019

HAL is a multi-disciplinary open access archive for the deposit and dissemination of scientific research documents, whether they are published or not. The documents may come from teaching and research institutions in France or abroad, or from public or private research centers.
L'archive ouverte pluridisciplinaire HAL, est destinée au dépôt et à la diffusion de documents scientifiques de niveau recherche, publiés ou non, émanant des établissements d'enseignement et de recherche français ou étrangers, des laboratoires publics ou privés. 


\title{
Temperature effect on the absorption spectrum of the hydrated
}

\section{electron paired with a lithium cation in deuterated water}

\begin{abstract}
Mingzhang Lin ${ }^{\mathrm{a}}$, Yuta Kumagai, ${ }^{\mathrm{a}}$ Isabelle Lampre ${ }^{\mathrm{b}}$, François-Xavier Coudert ${ }^{\mathrm{b}}$, Yusa Muroya ${ }^{\mathrm{c}}$, Anne Boutin $^{\mathrm{b}}$, Mehran Mostafavi ${ }^{\mathrm{b} 1}$, and Yosuke Katsumura ${ }^{\mathrm{a}, \mathrm{c}}$

a Department of Nuclear Engineering and Management, School of Engineering, The University of Tokyo, Hongo 7-3-1, Bunkyo-ku, Tokyo 113-8656, Japan.

${ }^{\mathrm{b}}$ Laboratoire de Chimie Physique/ELYSE, UMR 8000 CNRS / Univ Paris-Sud, Orsay, Bât. 349, F-91405 Orsay Cedex, France.

c Nuclear Professional School, School of Engineering, The University of Tokyo, 2-22 Shirakata Shirane, Tokai-mura, Nakagun, Ibaraki 319-1188, Japan.
\end{abstract}

\begin{abstract}
The absorption spectra of the hydrated electron in 1.0 to $4.0 \mathrm{M} \mathrm{LiCl}$ or $\mathrm{LiClO}_{4}$ deuterated water solutions were measured by pulse radiolysis techniques from room temperature to $300{ }^{\circ} \mathrm{C}$ at a constant pressure of $25 \mathrm{MPa}$. The results show that when the temperature is increased and the density is decreased, the absorption spectrum of the electron in presence of a lithium cation is shifted to lower energies. Quantum classical molecular dynamics (QCMD) simulations of an excess electron in bulk water and in the presence of a lithium cation have been performed to compare with the experimental results. According to the QCMD simulations, the change in the shape of the spectrum is due to one of the three $p$-like excited states of the solvated electron destabilized by core repulsion. The study of $s \rightarrow p$ transition energies for the three $p$ excited states reveals that for temperatures higher than room temperature, there is a broadening of each individual $s \rightarrow p$ absorption band due to a less structured water solvation shell.
\end{abstract}

\footnotetext{
${ }^{1}$ Corresponding authors : Mehran Mostafavi : mehran.mostafavi@lcp.u-psud.fr, and Yosuke Katsumura : katsu@n.t.u-tokyo.ac.jp
} 


\section{Introduction}

Observed for the first time in aqueous solutions of carbonate salts, ${ }^{1}$ the hydrated electron has been the subject of extensive works ever since. Its absorption spectrum was determined in this first study and appeared to be a broad, structureless band with a maximum around $715 \mathrm{~nm}$ in pure water. Because of the great interest of water in chemistry, biochemistry and physics, the structure of the hydrated electron remains a subject of intense research, both experimentally $\mathrm{y}^{2-8}$ and theoretically ${ }^{9-11}$. Several simulations of the hydrated electron were performed. ${ }^{12-16}$

The properties of the solvated electron depend on several factors such as the solvent, the temperature, the pressure or the presence of salt in solution. For instance, at room temperature, the maximum of its absorption band is located around $525 \mathrm{~nm}$ in glycerol, $715 \mathrm{~nm}$ in water and $2300 \mathrm{~nm}$ in diethyl ether. The optical absorption band shifts to higher energies with increasing pressure up to 2000 bar; the shift is larger in primary alcohols than in water ${ }^{17}$ or ethylene glycol. ${ }^{18} \mathrm{~A}$ rise in the temperature induces a red shift of the solvated electron absorption spectrum. Pulse radiolysis experiments show that in water and several alcohols the maximum of the absorption band shifts from visible to the near IR. ${ }^{19-22}$

For more than 35 years, the reactivity of the hydrated electron with different solutes, such as aliphatic, aromatic or heterocyclic compounds, and also anions and cations, has been widely studied mainly by pulse radiolysis. ${ }^{23-25}$ The data about the reduction of metal ions have been compiled in 1988 and $1995 .{ }^{26}$ Pulse radiolysis studies of aqueous solutions containing alkaline or earth alkaline metal ions have shown that the hydrated electron does not react with these metal ions but forms ion pairs. The first publication on the effect of non reactive metal cations on the absorption spectrum of the hydrated electron was published in $1965 .{ }^{27}$ These pulse radiolysis measurements in very concentrated aqueous solutions of $\mathrm{KF}(12.2 \mathrm{M}), \mathrm{MgCl}_{2}$ $(4.6 \mathrm{M}), \mathrm{NaClO}_{4}(10 \mathrm{M})$ and $\mathrm{LiCl}(15 \mathrm{M})$ showed that the absorption maximum of the solvated electron shifts from $720 \mathrm{~nm}$ in neat water to shorter wavelengths and that the shape of the absorption band remains similar. The origin of that blue shift was attributed to a contraction of the radius of the electron cavity due to the presence of the cation close to the electron. ${ }^{28}$ Then, a few studies mentioned a blue shift of the absorption spectra of the solvated electron in concentrated alkaline salts solutions, in water, ${ }^{29-31}$ in ethers and ammonia, ${ }^{32-35}$ in alcohols ${ }^{36}$ or in frozen aqueous solutions, ${ }^{37,38}$ without giving a global explanation of the phenomena. They only reported an electrostatic effect of the cation on the ground and/or first excited state of the solvated electron due to the decrease of the electron cavity size. The first systematic study on the salt concentration effect on the hydrated electron absorption spectrum 
was done in very concentrated $(0-15 \mathrm{M})$ aqueous solutions of $\mathrm{LiCl}^{39}$ It has been shown that increasing the salt concentration induces a non-uniform blue shift explained by the formation of local microstructures, and that the absorption spectrum evolves differently in the low and high energy sides. In recent years, thanks to the development of ultrafast laser pump-probe setup, ${ }^{40}$ a few publications ${ }^{41,42}$ noted a blue shift of the absorption band of the hydrated electron in the presence of a strong concentration of $\mathrm{NaCl}$ and attributed it to a change in the hydration energy of the electron. In 1999, Krebs and co-workers resumed the work on $\mathrm{LiCl}$ aqueous solutions and showed that the blue shift increased continuously with the concentration without any change in the absorption band shape. ${ }^{43}$

More recently a general study on the influence of various non-reactive metal cations on the absorption spectrum of the hydrated electron has been done. ${ }^{44}$ The effect of the presence of a non-reactive metal cation upon the absorption spectra of the hydrated electron was measured in concentrated aqueous solutions of eight chloride and five perchlorate salts, with monovalent, divalent and trivalent non-reactive metal cations. A shift of the absorption band maximum toward shorter wavelengths that increases with the salt concentration but also with the cation charge has been observed. The spectral shift depends on the characteristics of the solution such as cation size (through charge densities) or dissociation degree of the salt (partial screening of the cation charge when incomplete dissociation). ${ }^{45}$

Quantum simulations have indicated that the ground state of the hydrated electron is an s-like localized state and the excited states are three non-degenerate $p$-like states, also bound and localized, followed by a band of delocalised states; hence, the broad absorption band of the electron corresponds mostly to an $s \rightarrow p$ transition with the contribution of a transition between the bound state to the continuum at high energy. ${ }^{9,12,13,16}$ Recent three-pulses experiments on photoionization of water corroborated that attribution. ${ }^{46,47}$ Lately, molecular dynamics simulations showed the possible formation of a contact cation-electron pair in the case of sodium cation. Spectral simulations of the pair revealed a blue shift of about $0.3 \mathrm{eV}$ from the hydrated electron spectrum attributed to a destabilization of the $p$-like state in the close presence of the cation. ${ }^{48}$

In the present paper, we depict the results obtained by pulse radiolysis measurements of deuterated water solutions containing different concentrations of $\mathrm{Li}^{+}$cations at various temperatures. As $\mathrm{H}_{2} \mathrm{O}$ absorbs in the near IR spectral domain, deuterated water was used for the measurements. To explain the shift of the absorption spectra of the hydrated electron due to the combined effects of temperature and salt concentration, mixed quantum classical 
molecular dynamics (QCMD) simulations of an excess electron in bulk water and in presence of a lithium cation at different temperatures have been performed.

\section{Experimental Section}

$\mathrm{LiCl}, \mathrm{LiClO}_{4}$, tert-butyl alcohol and $\mathrm{D}_{2} \mathrm{O}(99.9$ atom \% D) were purchased from Wako Pure Chemical Industries, Ltd., and used as received. All the solutions were freshly prepared using $\mathrm{D}_{2} \mathrm{O}$. The solutions were deaerated with high purity Ar before being loaded to the cell.

The pulse radiolysis experiments were carried out on the Linac electron accelerator of the Nuclear Professional School, the University of Tokyo. The energy and pulse duration of the electron beam were $35 \mathrm{MeV}$ and 10 or $50 \mathrm{~ns}$, respectively. The high-temperature/pressure flow cell was made of Hastelloy HC22 with sapphire windows. Details of the apparatus were described elsewhere. ${ }^{20,49,50}$ Here we give only some important parameters. The highest temperature and pressure for the flow cell guaranteed by the factory (Taiatsu Techno ${ }^{\circledR}$ ) are $400{ }^{\circ} \mathrm{C}$ and $40 \mathrm{MPa}$, respectively. The optical path length is $15 \mathrm{~mm}$. The flow system is composed of a pump, a preheater, a heater, a back-pressure regulator, and a power supply with a temperature control unit. Four thermocouples are used to monitor temperatures at the preheater and the heater; one of these thermocouples is placed inside the solution for monitoring the temperature of irradiated samples. Given the low solubility of metallic salts in water at very high temperature and the corrosion damage of the sapphire windows, the temperature was increased up to $300{ }^{\circ} \mathrm{C}$ only. The pressure for all the measurements was 25 $\mathrm{MPa}$.

For the measurements of absorption spectra, a pulsed Xenon lamp (SAX-100H lamp, SA200F power supply, and an LB-5 inductor box, products of Nissin Electronics Co., Ltd.) with an output energy of $50 \mathrm{~J} /$ flash was used as analyzing light. Various blocking filters were used to cut the scattered and multiple orders light - a ultraviolet cut-off filter up to $340 \mathrm{~nm}$ was used for $\lambda<520 \mathrm{~nm}$, a cut-off filter till $520 \mathrm{~nm}$ for $\lambda=520-900 \mathrm{~nm}$, and a IR transmitting filter above $850 \mathrm{~nm}$ was for $\lambda>850 \mathrm{~nm}$, respectively. The wavelength resolution of the detection system was $\pm 10 \mathrm{~nm}$ in the UV-vis and $\pm 20 \mathrm{~nm}$ in the near IR, respectively. Since the absorption spectrum of the hydrated electron is shifted to longer wavelength with increasing temperature, it is necessary to measure the absorption spectrum not only in the UV-vis domain (said $\lambda=300-850 \mathrm{~nm}$ ), but also in the near IR region $(\lambda>850 \mathrm{~nm})$. In order to 
measure the absorption spectrum under the same conditions, we used a removable mirror, two fixed monochromators and two photodiodes (a Si PIN photodiode Hamamatsu photonics, S1722-02 to measure from 400 to $960 \mathrm{~nm}$ and an InGaAs PIN photodiode, Hamamatsu photonics, G3476-05 to measure above $880 \mathrm{~nm}$ ) in the experimental setup. The mirror was used during the measurements in the IR spectral region while it was taken away for the measurement in the UV-vis domain. The photodiodes were connected to an oscilloscope (Hewlett Packard, Tektronix, TDS3054B). The Linac and the Xenon lamp triggering, the wavelength changing and blocking filters, as well as the data acquisition from the oscilloscope, were controlled by a PC through GPIB interfaces. As already reported by Bartels et al. $^{51}$ the secondary detector response introduces wavelength dependent distortions in transient kinetics signals. In our set-up, the kinetics measured with Si Pin photodiode are almost the same from 400 to $900 \mathrm{~nm}$ and those measured with InGaAs are also wavelength independent from 1000 to $1500 \mathrm{~nm}$, but differ from the kinetics measured by Si photodiode (cf. supplementary materials). Nevertheless, in this study, we are only interested in the absorption spectrum at a given time and not in the time evolution of the absorption bands, so the absorbance obtained just after the pulse by the two photodiodes were corrected with the same factor determined in the overlapping region from 880-920 nm.

The dosimetry was done with an $\mathrm{N}_{2} \mathrm{O}$-saturated $10 \mathrm{mM}$ KSCN aqueous solution, taking $G \varepsilon\left((\mathrm{SCN}) 2^{\circ-}\right)=5.2 \times 10^{-4} \mathrm{~m}^{2} / \mathrm{J}$ at $475 \mathrm{~nm} .{ }^{52}$ We could not measure the dose pulse by pulse because of the use of full-metal high-temperature cell, but the dose fluctuation is less than $5 \%$ during a daylong experiment.

\section{Results and Discussion}

Figure 1 shows the normalized absorption spectra of the hydrated electron in $\mathrm{D}_{2} \mathrm{O}$ in the presence of $0.2 \mathrm{M}$ tert-butyl alcohol at different temperatures. The inset shows the absorption spectra recorded just at the end of the electron pulse without normalization. As can be seen from the inset, the intensity of the absorption band decreases with increasing temperature. As the density decreases with temperature (from 1.1 at $25{ }^{\circ} \mathrm{C}$ to $0.82 \mathrm{~g} \mathrm{~cm}^{-3}$ at $300{ }^{\circ} \mathrm{C}$ ), the deposited dose decreases. But the lowering of the signal intensity of the solvated electron cannot be explained only by this decrease and it is essentially due to the acceleration of solvated electrons reactions with temperature inducing a faster decay of solvated electron. For better comparison of the spectra, we normalize the maximum absorbance at each temperature 
to 1.0. Obviously there is a significant red-shift (shift to longer wavelength) with increasing

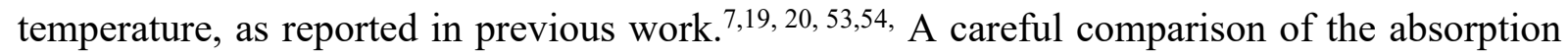
maxima $\left(E_{\max }\right)$ and the spectral shapes using Gaussian-Lorentzian functions as proposed by Jou et al. ${ }^{19}$ shows that these absorption spectra agree fairly well with those already reported. ${ }^{19}$, 7 That allows us to check the reliability of our experimental method and system.

Figure 2 show examples of the temperature dependent absorption spectra obtained by pulse radiolysis of $1.0 \mathrm{M} \mathrm{LiClO}_{4}, 1.0$ and $4.0 \mathrm{M} \mathrm{LiCl}$ in $\mathrm{D}_{2} \mathrm{O}$, respectively. Clearly, with increasing temperature, the absorption spectra of the hydrated electrons in these 3 solutions shift to the lower energy domain, similarly to those of the hydrated electrons in pure $\mathrm{D}_{2} \mathrm{O}$. However, in the presence of $\mathrm{Li}^{+}$cation at room temperature, the absorption maximum $\left(E_{\max }\right)$ is shifted to lower energy. The amplitude of the shift depends on the concentration of $\mathrm{Li}^{+}$. The blue shift of the absorption spectrum of the hydrated electron in concentrated salt solutions has been reported by several groups. ${ }^{27-31,38,39,41-45}$, Here, we compare $E_{\max }$ at room temperature in the presence of different concentrations of $\mathrm{LiCl}$ or $\mathrm{LiClO}_{4}$ with the data reported by Bonin et al., ${ }^{45}$ as shown in Table 1. It is worth noticing that the data by Bonin et al. were measured in light water at slightly lower temperature $\left(10^{\circ} \mathrm{C}\right.$ instead of $22{ }^{\circ} \mathrm{C}$ in $\mathrm{D}_{2} \mathrm{O}$ for this work) and for solutions of fixed molality (mol. $\mathrm{kg}^{-1}$ ) which deviates from concentration (mol. $\mathrm{L}^{-1}$ ) at high concentrations. Considering these differences the data obtained in this work agree well with the reported data. It is important to note that the isotope effect on the absorption spectra of the solvated electrons in water is very small. ${ }^{19,7}$

As can be seen from Figure 2, the absorption spectra recorded in $\mathrm{LiCl}$ solutions, show an additional absorption band in the UV region compared to those observed at $1.0 \mathrm{M} \mathrm{LiClO}_{4}$. This band corresponds to the absorption of $\mathrm{Cl}_{2}{ }^{\circ-}$ anion radical with $\lambda_{\max }=340 \mathrm{~nm}(3.65 \mathrm{eV})$ and $\varepsilon_{340 \mathrm{~nm}}=8800 \mathrm{M}^{-1} \mathrm{~cm}^{-1} 55$ formed according to the following fast reactions:

$$
\begin{aligned}
& \bullet \mathrm{OH}+\mathrm{Cl}^{-} \leftrightarrow \mathrm{ClOH}^{\bullet-} \\
& \mathrm{ClOH}^{\bullet-}+\mathrm{H}^{+} \rightarrow \mathrm{H}_{2} \mathrm{O}+\mathrm{Cl}^{\bullet} \\
& \mathrm{Cl}^{\bullet}+\mathrm{Cl}^{-} \leftrightarrow \mathrm{Cl}_{2}^{\bullet-}
\end{aligned}
$$

However, the absorption band of $\mathrm{Cl}_{2}{ }^{--}$is not broad at room temperature and the absorption coefficient is rather small $\left(\varepsilon_{450 \mathrm{~nm}} \sim 300 \mathrm{M}^{-1} \mathrm{~cm}^{-1}\right)$ as compared with that of hydrated electron $\left(\varepsilon_{450 \mathrm{~nm}}>3500 \mathrm{M}^{-1} \mathrm{~cm}^{-1}\right)$. Moreover, with increasing temperature, the spectral shift of the hydrated electron is much more significant than that of $\mathrm{Cl}_{2}{ }^{\bullet-}$. So, the absorption band of $\mathrm{Cl}_{2}{ }^{--}$ 
does not affect the principal part of the spectrum of the hydrated electron. A previous study by Kreitus already demonstrated that the absorption of $\mathrm{Cl}_{2}{ }^{--}$had very little effect on the analysis of the spectrum of the hydrated electron even for concentrations of $\mathrm{LiCl}>10 \mathrm{M} .{ }^{39} \mathrm{In}$ fact, according to the absorption spectra in Figure 2, the solutions containing $1.0 \mathrm{M} \mathrm{LiCl}$ and 1.0 $\mathrm{M} \mathrm{LiClO}_{4}$ give the same values of $E_{\max }$ at corresponding temperatures and they present also the same spectral shape for $\lambda>500 \mathrm{~nm}(2.48 \mathrm{eV})$. Although the use of $\mathrm{LiClO}_{4}$ gives more 'pure' absorption spectra of the hydrated electron, high concentration of perchlorate might be harmful to the sapphire windows and the tubing of flow system, especially at elevated temperatures. Therefore, we use $\mathrm{LiCl}$ instead of $\mathrm{LiClO}_{4}$ for high concentrations. In addition, the highest concentration in this work is limited to $4.0 \mathrm{M}$ given the low solubility of $\mathrm{LiCl}$ at high temperatures and the safety of our experimental system, although a concentration as high as $14 \mathrm{M} \mathrm{LiCl}$ has been reported for experiments at room temperature in a previous study. ${ }^{39}$

Figure 3 displays a comparison of the absorption spectra of solvated electrons at room temperature obtained by pulse radiolysis in a $\mathrm{D}_{2} \mathrm{O}$ solution containing $4.0 \mathrm{M} \mathrm{LiCl}$ and in pure $\mathrm{D}_{2} \mathrm{O}$ solution. The absorbance at $\lambda_{\max }$ for the two spectra is normalized to 1.0 and the spectrum of pure $\mathrm{D}_{2} \mathrm{O}$ is shifted to overlap with that of $4.0 \mathrm{M} \mathrm{LiCl}$ solution at lower energy side. Apparently in the presence of $4.0 \mathrm{M} \mathrm{LiCl}$, the absorption spectrum of solvated electrons broadens slightly but significantly. This spectral broadening becomes more and more pronounced with increasing $\mathrm{LiCl}$ concentration from 1.0 to 4.0 M. In inset of Figure 3, we report the absorption spectra after subtracting the contribution of $\mathrm{Cl}_{2}{ }^{-}$. We note that the spectral broadening in the presence of high concentration metallic salt is said to be still an arguable subject. ${ }^{39,45,56}$ Bonin $^{45}$ and Marbach ${ }^{56}$ claimed the spectral stability of the absorption spectrum of solvated electrons observed in concentrated salt solutions in water or in mixtures of THF/water by laser photolysis experiments, while Kreitus ${ }^{39}$ reported a spectral broadening with increasing $\mathrm{LiCl}$ concentration by pulse radiolysis measurements.

We observe also a change in the shape of the absorption spectrum with increasing temperature. As an example, Figure 4 shows a comparison of the absorption spectra at room temperature and $250{ }^{\circ} \mathrm{C}$, obtained by pulse radiolysis of a solution containing $1.0 \mathrm{M} \mathrm{LiCl}$. The absorbance maximum of the spectra has been normalized to 1.0 and shifted to the position at $25{ }^{\circ} \mathrm{C}$. It is clear that with increasing the temperature the band broadens at lower energy and narrows at higher energy. Therefore, the width becomes slightly larger at high temperature.

We have performed mixed quantum classical molecular dynamics (QCMD) simulations of an excess electron in bulk water and in presence of a lithium cation. As there is no isotopic effect 
in such calculations, the calculations are done in $\mathrm{H}_{2} \mathrm{O}$ and not in $\mathrm{D}_{2} \mathrm{O}$. The method and the simulation details are fully described elsewhere, ${ }^{16,48}$ and the main features are summarized hereafter. The excess electron only was treated quantum mechanically, using the BornOppenheimer approximation. The forces acting on each classical degree of freedom were the Hellmann-Feynman forces as well as those arising from the empirical models used for the water ${ }^{57}$ and the cation. ${ }^{58}$ The excess electron-water interactions were modelled using the pseudopotential developed by Turi and Borgis ${ }^{59}$ and the electron- $\mathrm{Li}^{+}$pseudopotential was a one-electron semilocal pseudopotentials proposed by Durand and Barthelat ${ }^{60}$ and optimized in previous work. ${ }^{61}$

It has been proposed that cation concentration effects experimentally observed on systems containing a solvated electron and alkali cations are mainly due to the mean electron-cation distance. ${ }^{61}$ Pursuing this approach, simulations of one electron and one $\mathrm{Li}^{+}$cation in bulk water were performed with additional constraints to allow the electron-cation distance $d$ to fluctuate around certain equilibrium values, using the quantum umbrella sampling method. ${ }^{62}$ To mimic the experimental effect of cation concentration, the simulations of the present study were performed for both $d \sim 2.5 \AA$ and $d \sim 4 \AA$. Shorter distance simulates higher concentration of cation, and lower distance that of lower concentration of metal cation.

The UV-Vis absorption spectra of the hydrated electron and a lithium cation in bulk water at different thermodynamic state points are shown in the lower panels of Figure 5, for a system where the hydrated electron is kept at a distance $d \sim 2.5$ and $4 \AA$ from the $\mathrm{Li}^{+}$cation. The spectra of the hydrated electron without cation in bulk water at the same thermodynamic conditions are shown in upper panel of Figure 5 for comparison. To describe quantitatively the position of the UV-Vis absorption spectrum calculated from QCMD simulations, we have calculated the mean position of the absorption band by integrating over this band:

$$
E_{\text {mean }}=\frac{\int E \times I(E) d E}{\int I(E) d E}
$$

This quantity and the position of the maximum of the absorption band, $E_{\max }$, have similar trends, but $E_{\text {mean }}$ is subject to much smaller statistic uncertainty than $E_{\max }$. The mean transition energy of the UV-Vis absorption spectrum, $E_{\text {mean }}$, is reported in Table 2 for the electron in bulk water, as well as the $\left\{\mathrm{e}_{\mathrm{aq}}{ }^{-}, \mathrm{Li}^{+}\right\}$systems with $d \sim 2.5 \AA$ and $d \sim 4.0 \AA$. We observe that when the temperature is increased and the density is decreased, the absorption spectrum of the 
electron in the presence of a lithium cation is shifted to lower energies, but this shift is smaller than that of the electron in bulk water. Moreover, the closer the hydrated electron and the cation are, the smaller the shift is. In the case of $\mathrm{Ag}^{+}$, the ion is reduced by the solvated electron to yield a neutral $\mathrm{Ag}^{0}$ atom in an excitonic state, ${ }^{63}$ the spectrum of which exhibits very little temperature- or density-dependence. ${ }^{64}$

Also presented in Table 2 the shifts:

$\Delta E_{\text {mean }}(d)=E_{\text {mean }}\left(\mathrm{e}_{\mathrm{aq}}{ }^{-}, \mathrm{Li}^{+} ; d\right)-E_{\text {mean }}\left(\mathrm{e}^{-}\right)$

between the absorption band in bulk water without cation and with the lithium cation at distance $d$, for a given temperature and density. These blue shifts are a measure of the influence of the cation on the hydrated electron, and it was experimentally observed that they grow with cation concentration. ${ }^{43-45}$ The experimental dependence on cation concentration was shown to be related to the dependence on electron-cation distance observed in simulation. We show here that this trend persists at temperatures higher than room temperature, in good agreement with the experimental results. We also show that, for a given electron-cation distance, higher temperatures lead to higher absorption spectrum shifts.

The evolution of $E_{\max }$ with temperature obtained by pulse radiolysis experiments (Figure 6 upper) is almost the same whatever the salt concentration. That means that the temperature effect on the absorption band is much larger than the salt effect. The shifts as a function of temperature of $E_{\text {mean }}$ calculated by QCMD simulations is also reported (Figure 6 bottom). Obviously, the results are consistent.

Finally, the spectra of the hydrated electron at $2.5 \AA$ of the $\mathrm{Li}^{+}$(Figure 5) exhibit a significantly larger Full Width at Half Maximum than that of the hydrated electron in bulk water under the same thermodynamic conditions (Table 2). The change in the shape of the spectrum and the existence of a shoulder are due to one of the three $p$-like excited states of the solvated electron (the one with $\Sigma$ symmetry, its orbital pointing in the direction of the cation) being destabilized by core repulsion. This effect was previously shown in other systems. ${ }^{61}$ The shoulder on the high-energy wing of the absorption spectrum is only obtained at room temperature. This result corroborates with the broadening of the spectrum reported in Figure 3. The study of $s \rightarrow p$ transition energies for the three $p$ excited states reveals that for temperatures higher than room temperature, there is a broadening of each individual $s \rightarrow p$ absorption band due to less structured water solvation shell. This broadening leads to higher overlap between the three bands and the absence of a high-energy shoulder on the resulting 
spectrum. Consequently, at high temperature and in the presence of metal cation, the shape of the absorption band changes while its width is roughly the same (Table 2). The experimental results reported on Figure 4 can be understood by that fact.

\section{Conclusion}

The increase in the temperature and the increase in the concentration of non-reactive metal cation have opposite effects. With temperature the absorption spectra of the solvated electron shifts to the red whereas in the presence of a salt it shifts to the blue. When both effects are present, the shift intensity and the shape of the absorption spectra are modified. However, the effect of the temperature on the absorption spectrum of the solvated electron is stronger than that of the presence of non-reactive metal cation even up to $4 \mathrm{M}$. QCMC simulations reveal that in the presence of the non-reactive metal cation, the width of the absorption band is broadened. The perturbation of the three $s \rightarrow p$ optical transitions by changing the solvation shell of the solvated electron accounts for such broadening.

\section{Acknowledgments}

We are grateful to Mr. T. Ueda and Prof. M. Uesaka for their technical assistance in pulse radiolysis experiments and encouragement. This work was partly entrusted by the Ministry of Education, Culture, Sports, Science and Technology (MEXT), Japanese Government, as a "Fundamental R\&D program on water chemistry of supercritical pressure water under radiation field". 


\section{References}

${ }^{1}$ Hart, E.J.; Boag, J.W. J. Am. Chem. Soc. 1962, 84, 4090-4095.

${ }^{2}$ Migus, A; Gauduel, Y.; Martin, J.L.; Antonetti, A. Phys. Rev. Lett. 1987, 58, 1559.

${ }^{3}$ Gauduel, Y.; Pommeret, S.; Migus, A.; Yamada, N.; Antonetti, A. J. Am. Chem. Soc. 1990, 112, 2925.

${ }^{4}$ Long, F. H.; Lu, H.; Eisenthal, K. B. Phys. Rev. Lett. 1990, 64, 1469.

${ }^{5}$ Alfano, J. C.; Walhout, P. K.; Kimura, Y.; Barbara, P. F. J. Chem. Phys. 1993, 98, 5996.

${ }^{6}$ Laenen, R.; Roth, T. J. Mol. Struct. 2001, 598, 347.

${ }^{7}$ Bartels, D.M.; Takahashi, K.; Cline, J.A.; Marin, T.W.; Jonah, C.D. J. Phys. Chem. A, 2005, 109, 1299.

${ }^{8}$ Lian, R.; Crowell, R. A.; Shkrob, I. A. . J. Chem. Phys. A. 2005, 109, 1510.

${ }^{9}$ Schnitker, J.; Motakabbir, K.; Rossky, P. J.; Friesner, R. Phys. Rev. Lett. 1988, 60, 456, and Schnitker, J.; Rossky, P. J. J. Chem. Phys. 1987, 86, 3471.

${ }^{10}$ Walqvist, A.; Martyna, G.; Berne, B. J. J. Phys. Chem. 1988, 92, 1721.

${ }^{11}$ Neria, E.; Nitzan, A.; Barnett, R. N.; Landman, U. Phys. Rev. Lett. 1991, 67 (8), 1011.

${ }^{12}$ Rossky, P. J.; Schnitker, J. J. Phys. Chem. 1988, 92, 4277.

${ }^{13}$ Motakabbir, K. A.; Schnitker, J.; Rossky, P. J. J. Chem. Phys. 1989, 90, 6916.

${ }^{14}$ Ludwig, V.; Coutinho, K.; Canuto, S. Phys. Rev. Lett. B 2004, 70, 214110(1-4).

${ }^{15}$ Bratos, S.; Leicknam, J.C. Chem .Phys. Lett. 1996, 261, 117-122, and Bratos, S.; Leicknam, J.C.; Borgis, D.; Staib, A. Phys. Rev. E 1997, 55, 7217.

${ }^{16}$ Nicolas, C.; Boutin, A.; Levy, B.; Borgis, D. J. Chem. Phys. 2003, 118, 9689.

${ }^{17}$ Jou, F.Y.; Freeman, G. R. J. Phys. Chem. 1977, 81, 909-915.

${ }^{18}$ Jou, F.Y.; Freeman, G. R. J. Phys. Chem. 1979, 83, 261-264.

${ }^{19}$ Jou, F.Y.; Freeman, G. R. J. Phys. Chem. 1979, 83, 2383-2387.

${ }^{20}$ Wu, G.; Katsumura, Y.; Muroya, Y.; Li, X.; Terada, Y. Chem. Phys. Lett. 2000, 325, 531.

${ }^{21}$ Mostafavi, M.; Lin, M.; He, H.; Muroya, Y.; Katsumura, Y. Chem. Phys. Lett. 2004, 384, 52.

${ }^{22}$ Lampre, I.; Lin, M.; He, H.; Han, Z.; Mostafavi, M.; Katsumura, Y. Chem. Phys. Lett. 2005, 402, 192.

${ }^{23}$ Hart, E. J.; Gordon, S.; Thomas, J. K. J. Phys. Chem. 1964, 68, 1271.

${ }^{24}$ Thomas, J. K.; Gordon, S.; Hart, E. J. J. Phys. Chem. 1964, 68, 1524.

${ }^{25}$ Baxendale, J. H.; Fielden, E. M.; Keene, J. P. Proc. R. Soc. London, Ser. A 1965, 286, 320.

${ }^{26}$ (a) Buxton, G. V.; Greenstock, C. L.; Philip Helman, W.; Ross, A. B. J. Phys. Chem. Ref. Data 1988, 17, 513, and (b) Buxton, G. V.; Mulazzani, Q.G.; Ross, A. B. J. Phys. Chem. Ref. Data 1995, 24, 1055.

${ }^{27}$ Anbar, M.; Hart, E. J. J. Phys. Chem. 1965, 69, 1244.

${ }^{28}$ Stein,G.; Treinin, A. Trans. Faraday. Soc. 1960, 56, 1393.

${ }^{29}$ Peled, E.; Meisel, D.; Czapski, G. J. Phys. Chem. 1972, 76, 3677.

${ }^{30}$ Woods, R. J.; Lesigne, B.; Gilles, L.; Ferradini, C.; Pucheault, J. J. Phys. Chem. 1975, 79, 2700. 
${ }^{31}$ Hankiewicz, E.; Schulte-Frohlinde, D. J. Phys. Chem. 1977, 81, 2614-2618.

${ }^{32}$ Bockrath, B.; Dorfman, L. M. Pulse radiolysis studies. XXII. J. Phys. Chem. 1973, 77, 1002.

${ }^{33}$ Salmon, G. A.; Seddon, W. A.; Fletcher, J. W. Can. J. Chem. 1974, 52, 3259.

${ }^{34}$ Fletcher, J. W.; Seddon, W. A. J. Phys. Chem. 1975, 77, 3055.

${ }^{35}$ Seddon, W. A.; Fletcher, J. W.; Sopchyshyn, F. C.; Catterall, R. Can. J. Chem. 1977, 55, 3356.

${ }^{36}$ Hickel, B. J. Phys. Chem. 1978, 82, 1005.

${ }^{37}$ Kroh, J.; Polevoi, P. Radiat. Phys. Chem. 1978, 11, 111.

${ }^{38}$ Czerwik, Z.; Wypych, M.; Kroh, J. J. Radioanal. Nucl. Chem. Art. 1986, 101, 275.

${ }^{39}$ Kreitus, I. V. J. Phys. Chem. 1985, 89, 1987.

${ }^{40}$ Yokoyama, K.; Silva, C.; Son, D. H.; Walhout, P. W.; Barbara, P. F. J. Phys. Chem. A 1998, 102, 6957-6966.

${ }^{41}$ Gelabert, H.; Gauduel, Y. J. Phys. Chem. 1996, 100, 13993.

${ }^{42}$ Assel, M.; Laenen, R.; Laubereau A. J. Phys. Chem. A 1998, 102, 2256.

${ }^{43}$ Asaad, A. N.; Chandrasekhar, N.; Nashed, A. W.; Krebs, P. J. Phys. Chem. A 1999, 103, 6339.

${ }^{44}$ Bonin, J.; Lampre, I.; Soroushian, B.; Mostafavi, M. J. Phys. Chem. A 2004, 108, 6818.

${ }^{45}$ Bonin, J.; Lampre, I.; Mostafavi, M. Radiat. Phys. Chem. 2005, 74, 288.

${ }^{46}$ Son, D. H.; Kambhampati, P.; Kee, T. W.; Barbara, P. F. Chem. Phys. Lett. 2001, 342, 571.

${ }^{47}$ Son, D. H.; Kambhampati, P.; Kee, T. W.; Barbara, P. F. J. Phys. Chem. A 2001, 105, 8269.

${ }^{48}$ Spezia, R.; Nicolas, C.; Archirel, P.; Boutin, A. J. Chem. Phys. 2004, 120, 5261.

${ }^{49}$ Mostafavi, M.; Lin, M.; Wu, G.; Katsumura, Y.; Muroya, Y. J. Phys. Chem. A 2002, 106, 3123.

${ }^{50}$ Katsumura, Y. in 'Charged Particle and Photon Interactions with Matter', eds. Mozumder A.; Hatano, Y. Marcel Dekker Inc., New York, 2004, p. 697.

${ }^{51}$ Cline, J. A. ; Jonah, C. D. ; Bartels, D. M. Rev. Sci. Instr. 2002, 73, 3908.

52 Buxton, G. V.; Stuart, C. R. J. Chem. Soc, Faraday Trans., 1995, 91, 279.

${ }^{53}$ Michael, B. D.; Hart, E. J.; Schmidt, K. H. J. Phys. Chem., 1971, 75, 2798.

${ }^{54}$ Christensen, H.; Sehested, K. J. Phys. Chem. 1986, 90, 186-190.

${ }^{55}$ Jayon, G. G.; Parsons, B. J.; Swallow, A. J. J. Chem. Soc., Faraday Trans. 1, 1973, 69, 1597-1607.

${ }^{56}$ Marbach, W.; Asaad, A.N.; Krebs, P. J. Phys. Chem. A 1999, 103, 28-32.

${ }^{57}$ Berendsen, H. J. C. ; Postma, J. P. M. ; van Gunsteren, W. F. ; Hermans, J. in Interaction models for water in relation to protein hydratation; Reidel, Dordrecht, 1981.

${ }^{58}$ Åqvist, J. J. Phys. Chem. 1990, 94, 8021.

${ }^{59}$ Turi, L.; Borgis, D. J. Chem. Phys. 2002, 117, 6186.

${ }^{60}$ Durand, P.; Barthelat, J. C. Theoret. Chim. Acta 1975, 38, 283.

${ }^{61}$ Coudert, F.-X. ; Archirel, P. ; Boutin, A. J. Phys. Chem. B 2006, 110, 607.

${ }^{62}$ Borgis, D. ; Staib, A. J. Chem. Phys. 1996, 104, 4776.

${ }^{63}$ Spezia, R. ; Nicolas, C. ; Boutin, A. ; Vuilleumier, R. Phys. Rev. Lett. 2003, 91, 208304.

${ }^{64}$ Boutin, A. ; Spezia, R. ; Coudert, F.-X. ; Mostafavi, M. Chem. Phys. Lett. 2005, 409, 219. 
Table 1. Peak positions of the absorption maximum of the hydrated electron in light and heavy water solutions containing $\mathrm{LiCl}$ and $\mathrm{LiClO}_{4}$ at different concentrations.

\begin{tabular}{|c|c|c|c|}
\hline Salt & $\begin{array}{c}\text { Concentration } \\
{[\mathrm{M}]}\end{array}$ & $\begin{array}{c}\mathrm{E}_{\max }[\mathrm{eV}] \text { at } 22^{\circ} \mathrm{C} \\
\left.\text { (this work, in } \mathrm{D}_{2} \mathrm{O}\right)\end{array}$ & $\begin{array}{c}\mathrm{E}_{\max }[\mathrm{eV}] \text { at } 10{ }^{\circ} \mathrm{C} \\
\left.\text { (Bonin, et al. }{ }^{45 *} \text { in } \mathrm{H}_{2} \mathrm{O}\right)\end{array}$ \\
\hline $\mathrm{LiCl}$ & 1.0 & 1.75 & 1.786 \\
\hline $\mathrm{LiCl}$ & 2.0 & 1.78 & 1.812 \\
\hline $\mathrm{LiCl}$ & 4.0 & 1.82 & - \\
\hline $\mathrm{LiCl}$ & 5.0 & - & 1.852 \\
\hline $\mathrm{LiClO}_{4}$ & 1.0 & 1.77 & 1.812 \\
\hline
\end{tabular}

* The concentration unit used in Ref. 45 is $\mathrm{mol} / \mathrm{kg}$.

Table 2. Main characteristics (mean transition energy and width in $\mathrm{eV}$ ) of the UV-Vis absorption spectra of the electron at different thermodynamic state points, for the hydrated electron in bulk water and in presence of a lithium cation at distances $d \sim 4 \AA$ and $d \sim 2.5 \AA$.

\begin{tabular}{|c|c|c|c|c|c|c|c|c|c|}
\hline \multirow{2}{*}{$\mathrm{T}(\mathrm{K})$} & \multirow{2}{*}{$\rho\left({\left.\mathrm{g} . \mathrm{cm}^{-3}\right)}^{-3}\right)$} & \multicolumn{2}{|c|}{$\mathrm{e}^{-}$aq } & \multicolumn{3}{c|}{$\mathrm{e}^{-}{ }_{\mathrm{aq}} \mathrm{Li}^{+}(d \sim 4 \AA)$} & \multicolumn{3}{c|}{$\mathrm{e}^{-}{ }_{\mathrm{aq}} \mathrm{Li}^{+}(d \sim 2.5 \AA)$} \\
\hline & & $\mathrm{E}_{\text {mean }}$ & Width & $\mathrm{E}_{\text {mean }}$ & $\Delta \mathrm{E}_{\text {mean }}$ & Width & $\mathrm{E}_{\text {mean }}$ & $\Delta \mathrm{E}_{\text {mean }}$ & Width \\
\hline 298 & 1.00 & 1.97 & 0.72 & 2.05 & 0.08 & 0.72 & 2.10 & 0.13 & 0.87 \\
\hline 523 & 0.82 & 1.71 & 0.85 & 1.80 & 0.08 & 0.85 & 1.87 & 0.16 & 0.92 \\
\hline 623 & 0.63 & 1.53 & 0.77 & 1.62 & 0.09 & 0.77 & 1.74 & 0.21 & 0.85 \\
\hline
\end{tabular}




\section{Captions:}

Figure 1. Temperature dependence of the normalized absorption spectra of the hydrated electron in $\mathrm{D}_{2} \mathrm{O}$. Inset: absorption spectra recorded just after the electron pulse. ( $\left.\boldsymbol{\square}\right) 25,(\square)$

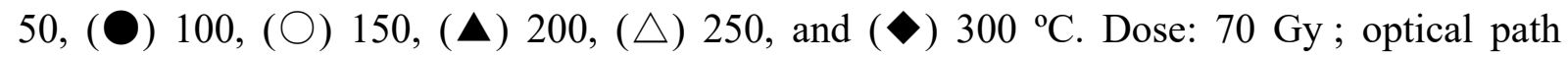
length : $15 \mathrm{~mm}$.

Figure 2. Normalized absorption spectra of the hydrated electron in $\mathrm{D}_{2} \mathrm{O}$ solutions containing $1.0 \mathrm{M} \mathrm{LiClO}_{4}, 1.0$ and 4.0 M LiCl as function of temperature. (ם) $25,(\square) 50,(\mathbf{O}) 100,(\bigcirc)$

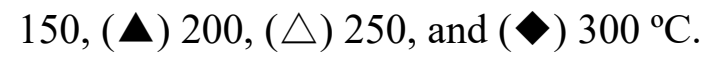

Figure 3. Comparison of the normalized absorption spectrum of solvated electrons in $4.0 \mathrm{M}$ $\mathrm{LiCl}\left(\square\right.$, deuterated solution) with that in pure $\mathrm{D}_{2} \mathrm{O}(\bullet)$ at room temperature. The spectrum in pure $\mathrm{D}_{2} \mathrm{O}$ is shifted to overlap that in $4.0 \mathrm{M} \mathrm{LiCl}$ solution at lower energy side. Inset: Same comparison but after subtraction of the contribution of $\mathrm{Cl}_{2}^{-\cdot}$ absorption. The $\mathrm{Cl}_{2}^{-\cdot}$ spectrum was obtained in the same experiment after complete disappearance of solvated electron.

Figure 4. Normalized absorption spectra of the solvated electron in $\mathrm{D}_{2} \mathrm{O}$ solution containing $1.0 \mathrm{M} \mathrm{LiCl}$ at $25^{\circ} \mathrm{C}(\bigcirc)$ and $250{ }^{\circ} \mathrm{C}(-)$ (Absorbance maximum normalized to 1 and shifted to the position at $25^{\circ} \mathrm{C}$ ).

Figure 5. UV-Vis absorption spectra of the hydrated electron in bulk water (upper panel) and in presence of a lithium cation at distance $\mathrm{d} \sim 2.5$ (lower panel) and $4 \AA$ (middle panel), at different thermodynamic state points (see Table 2).

Figure 6. Peak position of the absorption spectrum of the hydrated electron as a function of temperature. Top: $E_{\max }=f(T)$ experiments; Bottom: $E_{\text {mean }}=f(T)$; QCMD simulations. 


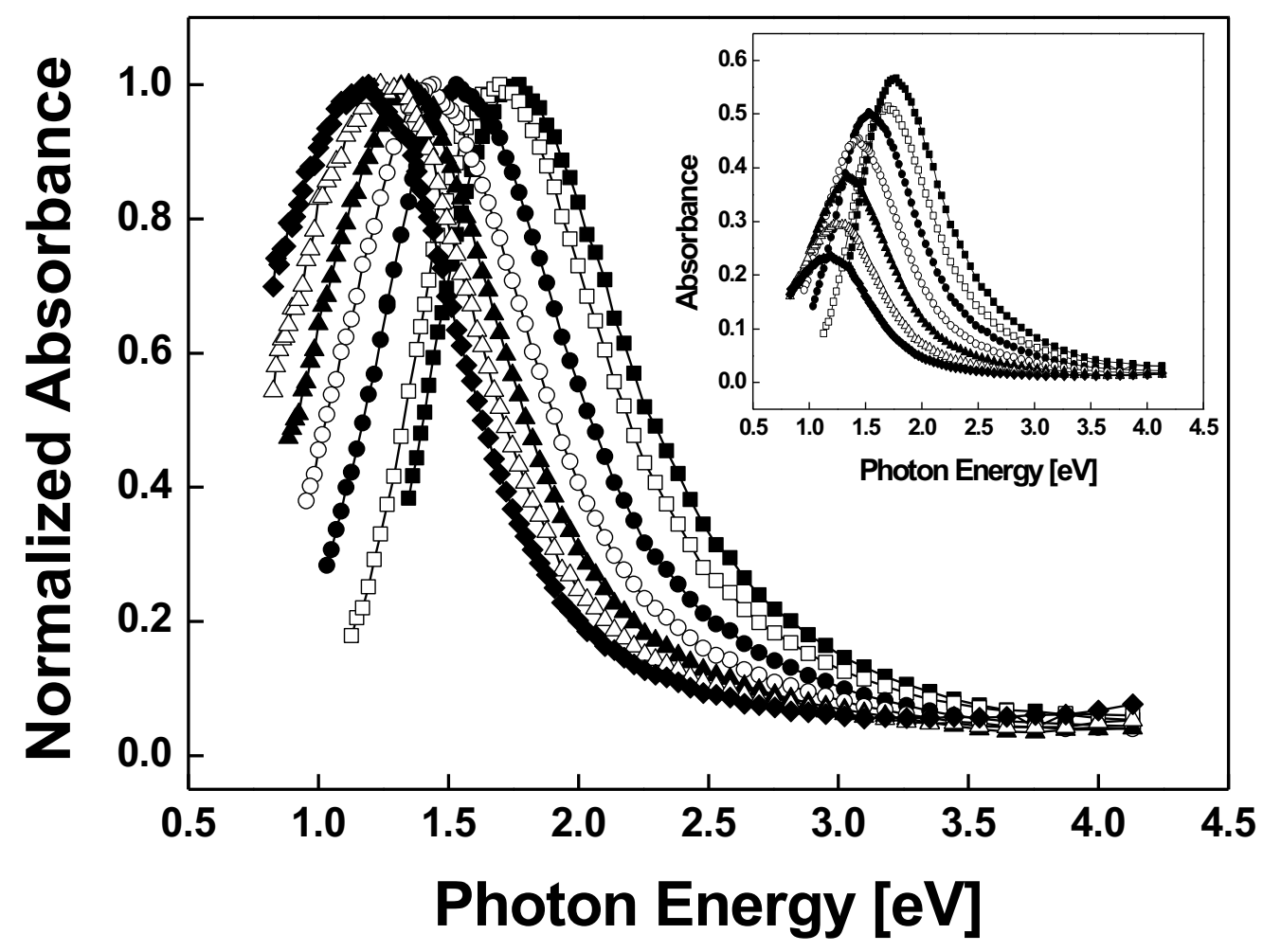

Figure 1. 


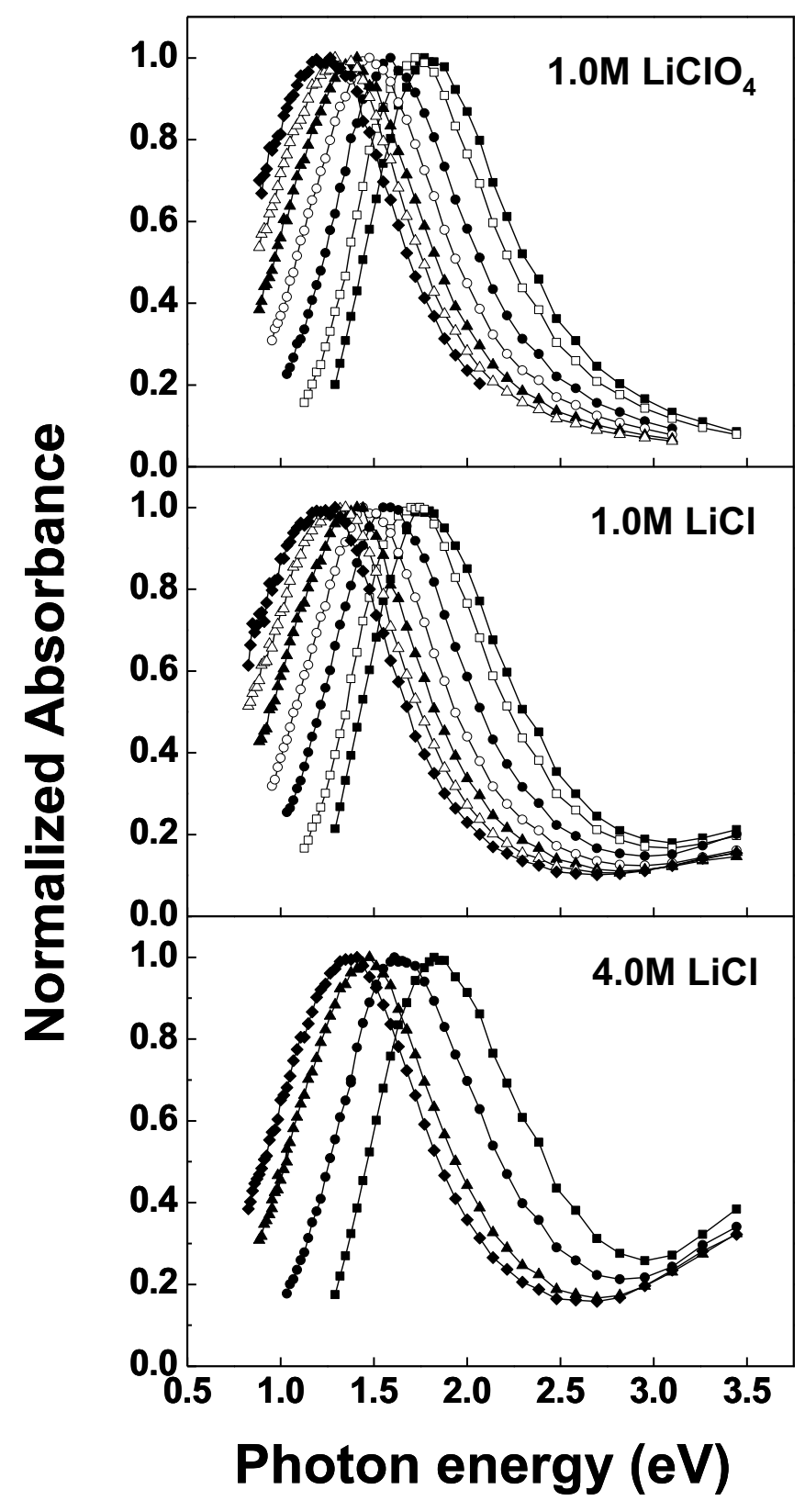

Figure 2. 


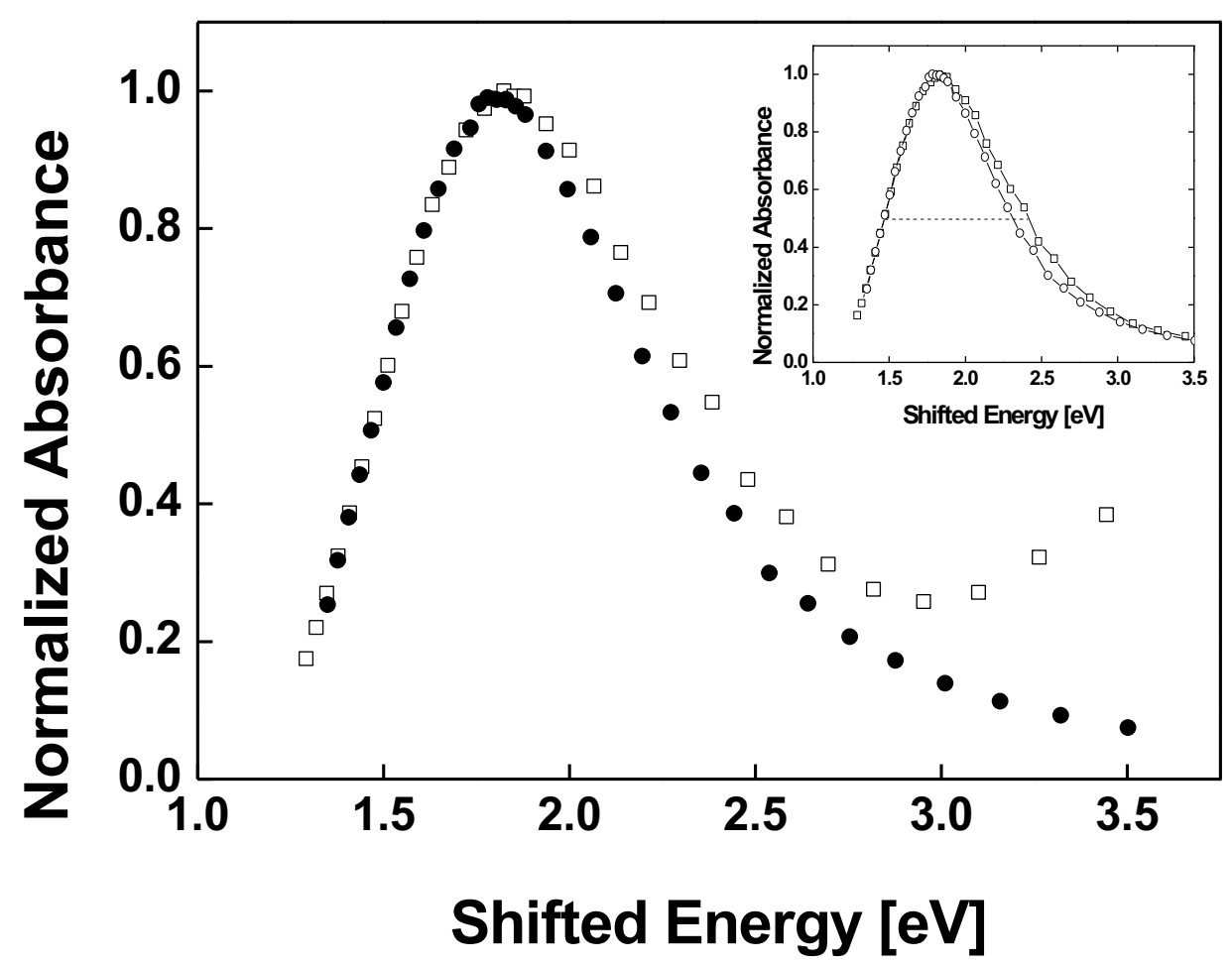

Figure 3. 


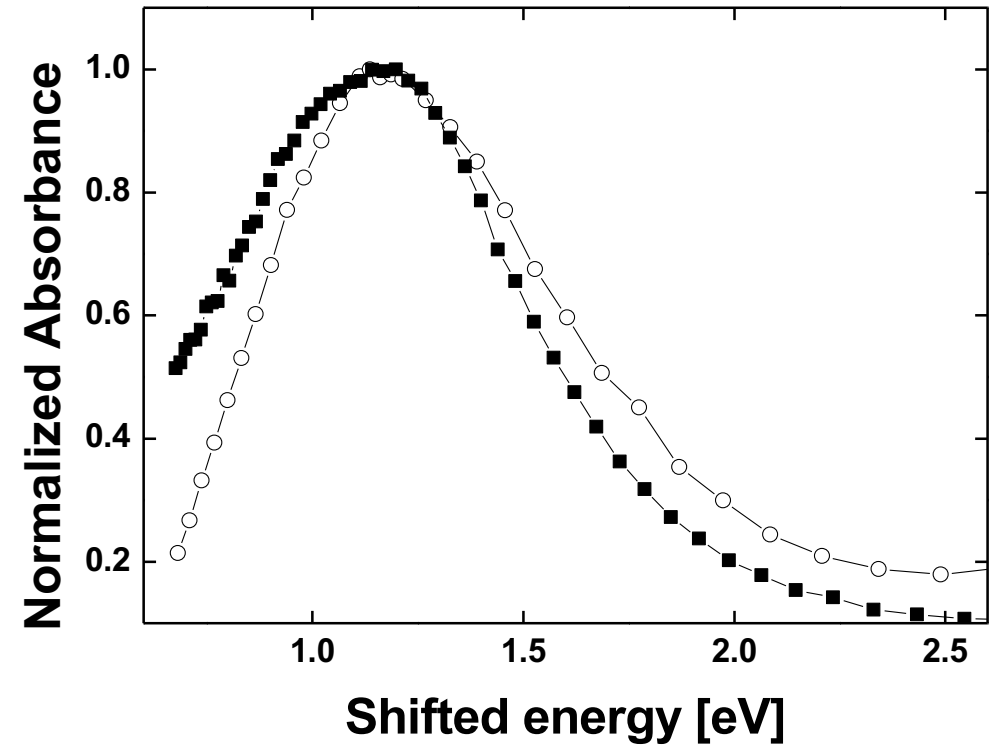

Figure 4. 


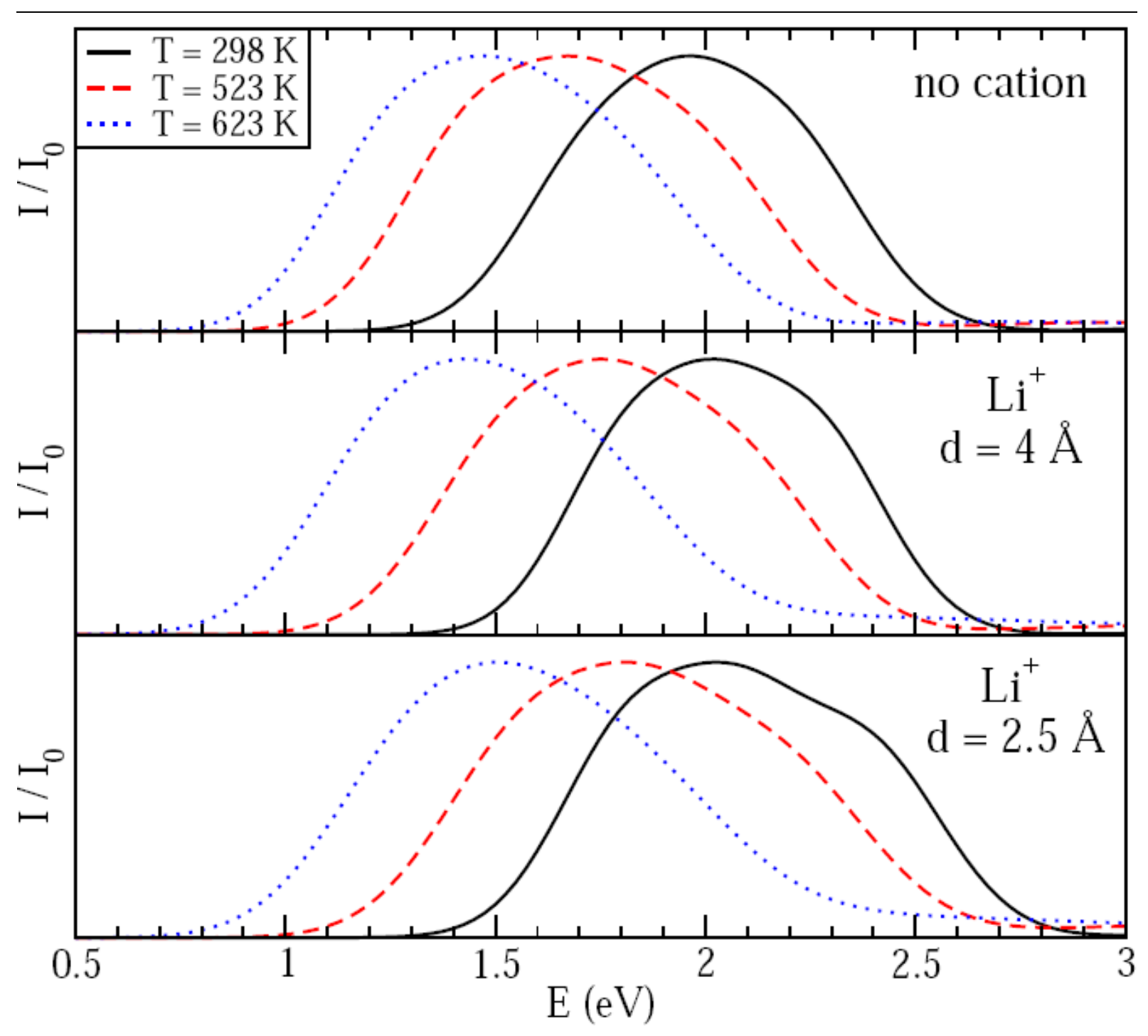

Figure 5 


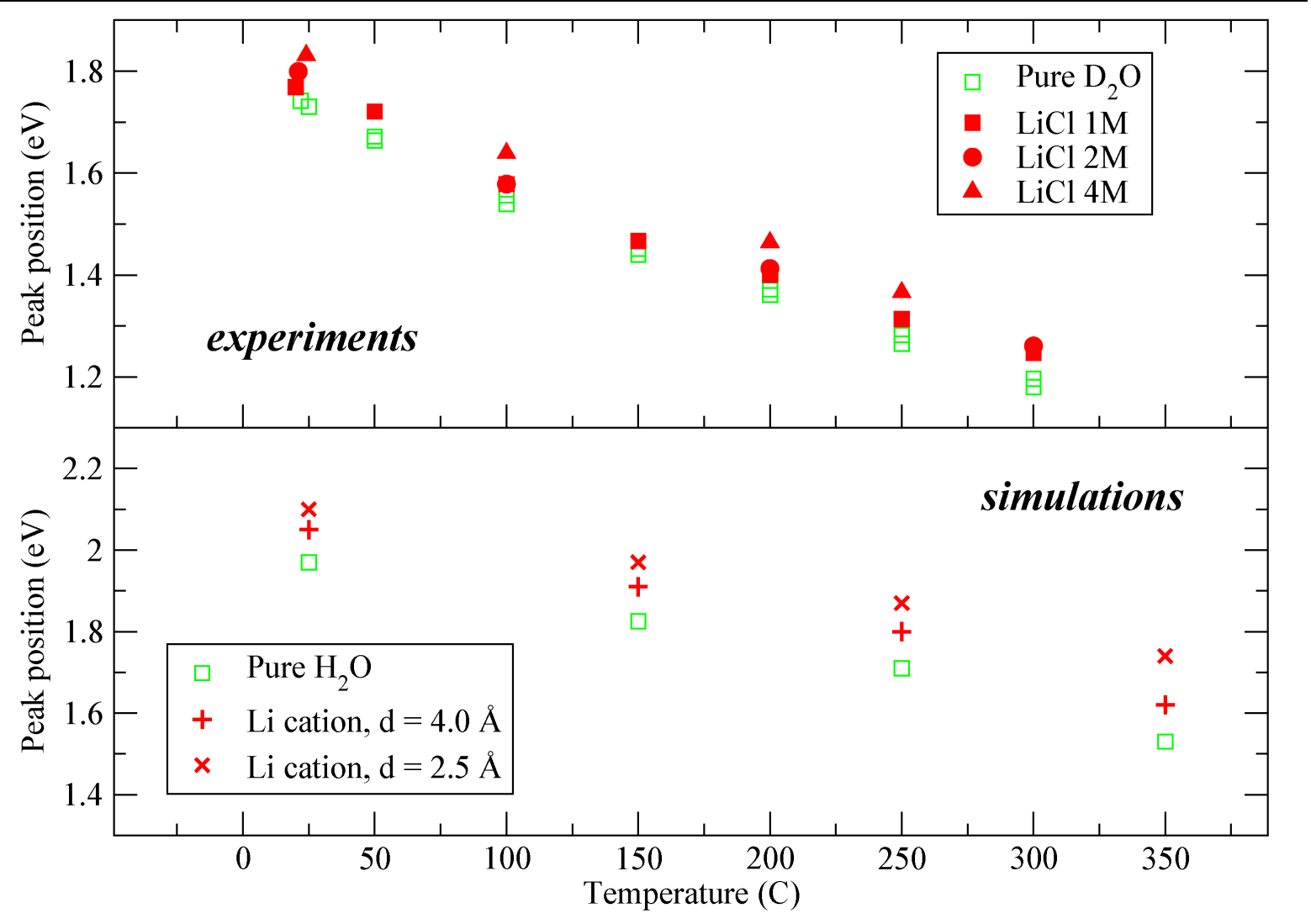

Figure 6. 


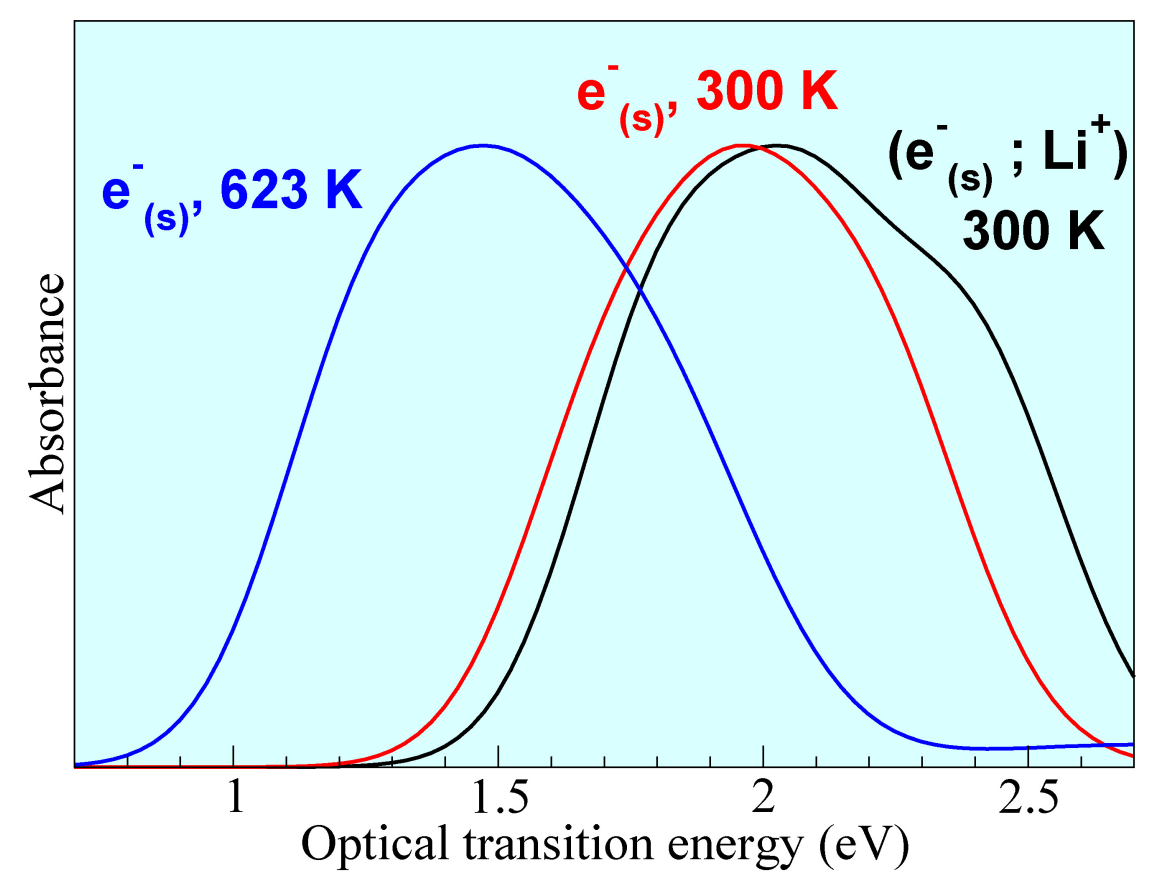

TOC graphics at the end of the manuscript 